\title{
SENTIDO DE VIDA Y MÍSTICA DESDE LAS MIRADAS DE MARTÍN VELASCO Y GARCÍA-BARÓ
}

\author{
ANGÉLICA MORALES ARIZMENDI \\ Universidad Pontificia Comillas
}

\begin{abstract}
RESUMEN: Este ensayo parte de la recogida de algunos criterios esenciales que ofrece el pensamiento filosófico occidental y del estudio de la fenomenología de la religión contemporánea para entrar en diálogo con la mística. En un segundo momento, exponemos las consideraciones al problema de la religión, acudiendo al pensamiento sobre lo absoluto desde una aproximación fenomenológica que salve a la relación religiosa de cualquier forma de sentimiento de consuelo o encubrimiento del mal. Como resultado de esto, señalamos las dificultades para asumir la analogía entre relación con Dios y relación interpersonal o empatía, como instrumento idóneo para explicar la relación religiosa. En un cuarto momento, intentamos la articulación de la experiencia matriz-ontológica y las experiencias culminantes ética y filosófica con la mística española. Con estos factores de transición, ofrecemos algunas conclusiones de la dialéctica de la vida y su sentido hacia la mística. Quedan así establecidas las bases antropológicas de la mística.
\end{abstract}

PALABRAS CLAVE: presencia; vida; sentido; experiencia; acontecimiento; misterio; trascendencia; absoluto; alteridad; mística; amor.

\section{Martín Velasco and García-Baró on the Meaning of life and mysticism}

ABSTRACT: This essay starts from the collection of essential criteria offered by Western philosophical thinking and of the comparative study of the phenomenology of contemporary religion. In a second moment, we present the considerations to the problem of religion, turning to thought on the absolute from a phenomenological approach that saves the religious relationship from any form of comfort or concealment of evil. As a result of this, we point out the difficulties in assuming the analogy between the relationship with God and interpersonal relationship or empathy, as an ideal instrument to explain the religious relationship. In a fourth moment, we try to articulate the matrix-ontological with the experiences ethical, philosophical with the Spanish mysticism. With these transition factors, we offer some conclusions of the dialectic of life and its sense towards mysticism. Thus, the anthropological bases of mysticism remain.

KEY WORDS: presence; life; meaning; experience; event; mystery; transcendence; absolute; otherness; mysticism; love.

Si la filosofía se define como un esfuerzo humano de radicalidad por entender racionalmente la totalidad de las cosas reales a partir de sus causas profundas, cobra enorme interés la actividad filosófica de pensadores contemporáneos que ahondan en el hecho religioso y sus formas previas, recuperando los misterios de la vida, el sentido y el amor.

Algunos elementos del estudio del fenómeno religioso de Juan Martín Velasco y otras tesis de Miguel García-Baró al pensar la situación fundamental de la existencia, pueden entrar en diálogo con la mística española del siglo XVI (cediendo alguna palabra a Teresa de Jesús y Juan de la Cruz). Lo interesante está en las convergencias para presentar un marco conceptual que nos permita avanzar y ampliar nuestra comprensión de la vida del místico entendida como la existencia ante Aquel presente que tiene y da Vida. Es un primer ensayo que 
no pretende resolver, sino formular algunas ideas para el estudio de la mística a partir de temas principales de la filosofía contemporánea: presencia, vida, sentido, esperanza absoluta, misterio, mal sinsentido.

\section{BREVE MIRADA A LA TRADICIÓN HISTÓRICO-FILOSÓFICA}

Una aproximación histórico-filosófica debe considerar los distintos momentos y métodos bajo los cuales se ha hecho filosofía para aplicar criterios que fundamentan la vida del místico.

Este recorrido opta por traer tan solo tres grandes momentos. La filosofía clásica, con Sócrates y Platón a la cabeza que marca un antes y un después en la concepción del hombre, de la ética y de la metafísica. Se eleva la mirada a la inteligencia (noûs) como patrimonio de los seres humanos y se llega a comprender la realidad dotada de sentido en su implicación moral. Una siguiente etapa es la que nos introduce en el pensamiento moderno sobre la subjetividad como fenómeno originario. Se pone la mirada en el centro existencial del hombre como radical individualidad.

Teniendo como base estas aportaciones, entra en consideración lo absoluto como fundamento de toda actividad religiosa, sobre todo, bajo la crítica a la relativización de la malignidad del mal, la superstición el narcisismo religioso, etc.

Tenemos pues, nuevas luces para el acercamiento a la mística. Se piensa desde la situación dialéctica de la vida humana como realidad misteriosa y como un yo libre y racional: capacitas Dei. Ahí situamos a Juan Martín Velasco y a Miguel García-Baró. Una continuación en el presente, de ese hecho tan sobresaliente en la historia espiritual de Occidente: la confluencia de la filosofía griega y el pensamiento bíblico. Reunión que marca un antes y un después para la religión.

Cuando Miguel García-Baró recurre, tal como lo hace en Sócrates y herederos o en su Introducción a la teoría de la verdad, a la idea de las navegaciones filosóficas como expuso Platón en el Fedón ${ }^{1}$, dibuja un mapa de perspectivas de la teoría de la verdad y de las distintas comprensiones del ser². Hacemos solo mención de estas navegaciones en la historia de Occidente y su clave de actividad filosófica para reconocer las ideas que abrieron en sentido radical la vida ética y filosófica hacia la mística.

En la primera salida filosófica, los pensadores hacen una primera navegación para pensar las cosas mismas, la naturaleza y la realidad. Con el fin de conocerlo todo nos ofrecieron una multitud de doctrinas que prometían explicar la naturaleza desde la naturaleza misma. Una segunda navegación, con

1 Recordamos que el Fedón es esa invitación constante a filosofar, y a la vez, el paradigma para llevarlo a cabo. Se nos exhorta a un modo filosófico de vida a la práctica permanente del discernimiento.

2 Para todo este apartado me he basado en $C f$. García-Baró, M., Sócrates y herederos, Salamanca, Sígueme, 2009, pp. 17-22. 
Anaxímenes de Mileto, la filosofía recurre al discurso (logos) como lugar primordial de la verdad. Significa que la verdad se presenta y deja captar en las cosas. Esto sirvió posteriormente a otras escuelas filosóficas para organizar el sistema de pensamiento de los primeros principios: sensación, visión intelectual, phrónesis o prudencia, noûs o inteligencia.

Es con Descartes, dirá García-Baró, cuando se revela la necesidad de una tercera navegación. Señala García-Baró que mucho le debe la historia del pensamiento a este gran navegante que abrió la vía introspectiva como experiencia de la subjetividad. El filósofo se esfuerza por pensar la necesidad de volver a las formas pre-predicativas del lugar de la verdad; filosofía, moral, religión y ciencia — de aquí hasta nuestros días - tienen en el sujeto individual su alfa y su omega. Queda así abierta la filosofía de la alteridad que apunta y hace posible una cuarta navegación ${ }^{3}$.

Entender el horizonte del mundo sin considerar los misterios que acontecen en él dejaría fuera toda ética. Con el afán filosófico de conocimiento, libertad y radicalismo, García-Baró introduce en su esquema la cuarta navegación: filosofía de la alteridad ${ }^{4}$. Aquí la cuestión de fondo es la distinción necesaria entre conocimiento filosófico y conocimiento natural. La idea es pensar modos esencialmente previos de instalación en la existencia por parte del hombre ${ }^{5}$. Seguir este hilo de pensamiento nos devuelve a la gran cuestión ético-socrática. Admirándose por la interrogación filosófica, «Sócrates afirmó que la vida del hombre, de cualquier hombre, no se puede vivir sin examen; en otras palabras, que la filosofía es necesaria y que hasta, probablemente, es el unum necessarium, lo absolutamente necesario, o parte esencial de él» ${ }^{6}$. La práctica radical de las virtudes morales llevan a la culminación de las virtudes intelectuales, sin intento alguno por invertirlas. Si es verdad que nada es peor que la ignorancia, esta tendrá una relación categórica con el mal. Así pues, valentía y su contrario —el miedo - serán determinantes para vivir en la verdad y su búsqueda o, el tranquilizador prestigioso del «parecer». Recordemos que el mundo de apariencias está tan a la mano que calma superficialmente la tan perfecta inquietud del alma. Y en el «humo» de apariencias — acentúa el autor-, el mal está a la mano.

Así, la cuarta navegación prolonga la tercera y se pone a considerar la pregunta por el absoluto y el mal para abrir una quinta vía de pensamiento. El hombre ha sido creado para el bien y es una realidad capaz de obrar conforme a él, pero es evidente que no lo ama desde el principio. La vida orientada hacia el bien no está dada, supone una larga, y nunca cerrada, actividad existencial. La tarea es penetrar en lo secreto de lo absoluto — de lo que «domina sobre todo

3 García-Baró, M., op. cit. p. 19.

4 Algunos contemporáneos piensan que García-Baró encontraría entre los principales navegantes de este nuevo intento a Kierkegaard, Rosenzweig, Buber, Levinas, Chalier, G. Marcel. (Cf. Rosales Meana, D., «Hablar en silencio. Cuatro Navegaciones», en: La filosofía y el Bien, Ápeiron Ediciones, Madrid, 2018, p. 105).

5 García-Baró, M., Vida y mundo, Madrid, Trotta, 1999, p. 90.

6 Cf. García-Baró, M., op. cit., pp. 14 ss. 
lo cambiante (yo, mundo, cosas, otros), de lo metafísico o trans-natural» ${ }^{7}-\mathrm{y}$ reformarlo todo desde ahí. Esta tesis es tan radical que considera que la experiencia absoluta del dolor destruye todo sentido y es imposible consolarlo; la malignidad del mal es injustificable ${ }^{8}$.

«El absoluto antinarcisismo de la actitud socrática, que no es una fe, sino que es la esencia misma de la vida humana en su sector más alto y profundo, puede exigir — exige, de hecho— superar la falsa objetividad, que se pretendía ya absoluta, de la actitud superficial»?.

Una vez expuestas las ideas de estas navegaciones hacemos una meditación de la experiencia religiosa en el escenario actual de la religión. Creemos que así se puede integrar la reflexión sobre la situación fundamental de la existencia y la presencia misteriofánica de la realidad como iniciación a la mística.

\section{DE LA EXPERIENCIA A LA ACTITUD FUNDAMENTAL Y DE LA ACTITUD AL MISTERIO}

Aunque Dios siempre se hace presente, su Presencia no es reconocida por el hombre distraído, de mirada superficial o perdido entre los bienes mundanos. Su reconocimiento es solo posible bajo ciertos preámbulos existenciales. El problema que se levanta, es que la realidad trascendente, por ser presencia inobjetivable, solo puede manifestarse a través de una realidad que forme parte del mundo, lugar de la experiencia humana de Dios.

Para mostrar esto, Martín Velasco reconoce que la oposición sistemática entre razón y religión no se establece solo por interpretaciones racionalistas o positivistas del hecho religioso, sino que la religión misma se sitúa en oposición a la «razón natural». Por tanto, el desafío será superar esta aparente antinomia razón-religión ${ }^{10}$. Para ello, el análisis del símbolo como un «logos interno", tiene un papel esencial para el reconocimiento de la Presencia, digamos que es un factor determinante. Ahondar en él permite incursionar en una dimensión de la existencia que configura un mundo específico y vital para el sujeto religioso. Las tres funciones creativas del símbolo son: de razón, de orden e inteligibilidad y de ejercicio de la existencia. Al «abrir el círculo estrecho de lo puramente biológico y lo puramente empírico en el nivel puramente corporal [...] el simbolismo opera esta ruptura no solo revelando una cara profunda de la realidad sino también una nueva dimensión de la existencia» ${ }^{11}$. Así,

Ibíd. p. 22.

8 Cf. García-Baró, M., De estética y mística, Salamanca, Sígueme, 2007, pp. 45-48.

9 Ibíd. p. 105.

10 Martín Velasco, J., «El mito y sus interpretaciones», en Revelación y pensar mítico, Madrid: CISC, 1970, pp. 5-43.

11 Martín Velasco, J., La religión en nuestro mundo, (Salamanca, Sígueme, 1978), p. 217; para este apartado, remitimos también a una lectura de la tercera parte del capítulo V, «El símbolo del encuentro y el lenguaje humano sobre Dios», en El encuentro con Dios, Madrid, Caparrós Editores, $3^{\text {a }}$ ed. 2007, pp. 278 ss. 
la experiencia religiosa es dar significado simbólico a las realidades del mundo convirtiéndolas en medios que comunican con la trascendencia ${ }^{12}$. Trazado este camino se entiende por qué Martín Velasco afirma que la actitud religiosa solo puede ser comprendida como una actitud simbolizante:

«Solo a partir de la apertura del horizonte humano que supone la relación del hombre con lo sagrado [mediación intramundana] y su expresión en los términos inmediatos del simbolismo religioso aparece la posibilidad tanto del pensamiento teológico sobre Dios como del pensamiento filosófico sobre el ser» ${ }^{13}$.

Esta misma idea la acentuó Mircea Eliade, al decir que el símbolo es lo que transforma el caos en orden haciendo posible la existencia y dotándola de sentido ${ }^{14}$.

Con estos presupuestos, «las constelaciones simbólicas en las que obtiene su primera expresión la "relación con lo sagrado" es fuente del pensamiento racional porque le ofrece los temas sobre los que éste se ejerce sin jamás agotarlos» ${ }^{15}$. Este logos permite al sujeto adentrarse en dimensiones más profundas de la realidad, aun cuando sean difíciles de reconocimiento, y le constituye el lugar originario de todo proceso simbolizador ${ }^{16}$. Así, el sujeto es un sujeto simbolizante que participa en un ejercicio permanente de superación de sí mismo mediante esta matriz del pensamiento. Digamos que es su condición de posibilidad. ¿Cómo se hace posible esta superación? La respuesta de Martín Velasco nos contasta que la particular trayectoria existencial es imprescindible:

«El redescubrimiento de Dios exige de nosotros una cura lenta de sosiego, de concentración, de interiorizacion, de contemplación, de disponibilidad, de gratuidad, de desasimiento, de libertad interior, de creatividad; necesitamos un largo periodo de rehabilitación para lo espiritual —no aislado de lo corporal —, lo personal —no equivalente a privado o individual $-[\ldots]$ la cultura científico técnica en que vivimos nos está atrofiando por haber creado un medio ambiente cultural y social en el que su ejercicio se hace en la práctica imposible» ${ }^{17}$.

De acuerdo con esta interpretación es inevitable el cultivo de actitudes y disposiciones para el reconocimiento de la Presencia de Dios en el mundo. Ya sea trascendiéndose o redescubriéndose a sí, el sujeto religioso se hace capaz de captar la huella del Misterio en su propia finitud. Ahora bien, si estas actitudes se convierten en las posibles noticias y orientaciones - hierofanías diría M. Eliade- hacia Dios, han de ser consideradas como el preámbulo antropológico

12 Cf. Eliade, M., "Consideraciones sobre el simbolismo religioso», Mefistófeles y el andrógino, Madrid, Guadarrama, 1969, pp. 216-258.

13 Martín Velasco. J., op. cit., p. 220.

14 Eliade, M., Mythes, rêves et mystères, p. 13. Citado por Juan Martín Velasco, Introducción a la fenomenología de la religión, Madrid, Trotta, 2006, p. 70.

15 Martín Velasco. J., op. cit., p. 223.

16 Ibid. p. 224.

17 Ibíd. p. 86. 
de la experiencia religiosa. Como ya se ve, el proyecto fenomenológico de Martín Velasco reclama que la actitud fundamental se convierta en un estadio preparatorio de la experiencia.

La actitud fundamental es la que permite el reconocimiento de la absoluta supremacía del Misterio, y su consecuencia inmediata será la confirmación de la condición trascendente del ser humano - tenemos expresiones de san Juan de la Cruz que se refieren a esta idea: "cayendo el alma en la cuenta», «toda ciencia trascendiendo»-, saberse humilde por la imposibilidad de poseer o retener el Misterio. Así que, el primer movimiento de la actitud permite al sujeto reconocer su alma e inaugurar el trascendimiento. En el origen está lo trascendente mismo, y lejos de ir más allá de las realidades del mundo, se hace presencia presente y dante en el acto. Por eso la actitud tiene carácter extático y salvífico: por ser vinculación con la necesidad, permite al sujeto fortalecer su relación con lo más íntimo de sí mismo, y a la vez, corroborar su libertad respecto del mundo en el que habita.

Cabe decir que este reconocimiento no puede liberarnos de las dificultades y obstáculos propios de la vida, y es que «la fe no arma para la solución de las tareas intramundanas» ${ }^{18}$. Descrito con palabras de Martín Velasco:

«La salvación religiosa no significa exactamente la superación de las dificultades intramundanas con que el hombre tropieza, ni la adquisición de unos bienes determinados, ni, por tanto, primariamente, la consecución de la felicidad que resulta del goce de los mismos. La salvación es la realización de la relación con esa realidad que vale y da sentido, que es y se justifica por sí misma, que es y es plenamente digna de ser ${ }^{19}$.

Ahora vayamos a la noción de experiencia, en particular la que se reconoce como experiencia de Dios, que es vivencia de algo completamente inabarcable. Se puede definir como la aprehensión inmediata del sujeto de algo que se le ofrece como dado: conocimiento que se asemeja a lo que Blondel define como «experiencia concreta $»^{20}$, y su enseñanza es adquirida con la práctica. Basta decir, como ejemplo, que tenemos experiencia del amor solo cuando amamos y somos amados. La experiencia de esta realidad última, independientemente de los sujetos que la vivan e interpreten, no se restringe ni se reduce a una cierta experiencia que se obtiene del conocimiento de objetos sensibles. No estamos autorizados a decir que experiencia es sólo sensible. Hablamos de conocimiento experiencial y no experimental.

Se puede concluir así, que la experiencia es el resultado de una "vivenciación» o consecuencia de la actitud religiosa antes referida.

18 Martín Velasco. J., Introducción a la Fenomenología de la religión., op. cit., p. 97.

19 Ibíd. p. 134.

20 Martín Velasco. J., «Proyecto de Fenomenología de la experiencia de Dios», en: La identidad de la mística, Fe y experiencia de Dios. Actas del Congreso Internacional de Mística homenaje a los 400 años de la beatificación de santa Teresa de Jesús, p. 64. 
Es importante decir que para Martín Velasco las distinciones mencionadas entre actitud y experiencia de la trascendencia deciden el criterio de autenticidad del hecho religioso. La experiencia no es el elemento central de la respuesta del sujeto, sino un derivado de la actitud fundamental, por tanto, si se toma como criterio de autenticidad, se pierde de vista la propiedad inevitable que corresponde a la respuesta humana: la de una actitud determinada que integra el trascendimiento personal y la condición absoluta de trascendencia del Misterio. Desde aquí, es la actitud la que adquiere el contenido que nos permite comprender la trascendencia. Martín Velasco lo resume así:

«La condición de supremo del Misterio ilumina la estructura de la actitud con la que el hombre reconoce su presencia. Pero, recíprocamente, el análisis de la actitud nos ayuda a comprender mejor la realidad que es su término. Así, ahora estamos en disposición de comprender mejor el significado del término «trascendencia», del que nos hemos servido frecuentemente para designar al Misterio. Éste es trascendente no porque esté más allá del resto de las realidades del mundo. El nervio del esquema de la trascendencia no es esta lejanía espacial a la que remite inmediatamente la imagen que utilizamos. El esquema que opera en el concepto de trascendencia es más bien dinámico, existencial y significa el hecho de que la realidad trascendente sólo puede hacerse presente al término de un acto de total trascendimiento del sujeto al que esa presencia va dirigida ${ }^{21}$.

Así que, la relación humana con el Misterio se vive permanentemente en una dialéctica de tensión: salvación-culpa, infinitud-finitud, dependencia-libertad, tiempo-eternidad, pregunta-explicación, llamada-respuesta; el yo, autoconciencia, es un actor que se ve interpelado por el Misterio. Por esto msmo la actitud de radical apertura a la Trascendencia da origen a la situación paradójica esencial: soy un ser finito, contingente y mortal, y soy un ser abierto al infinito queriendo infinitamente ser. Como se ve, el sujeto, aun condicionado por sus circunstancias históricas y culturales, vive alterado y en deseos de ser, de liberación y de salvación.

A la luz de estos datos y de las reflexiones que suscitan para Martín Velasco la noción de experiencia mística debe ser estudiada. Si tomamos como criterio de análisis las experiencias extrañas, poco comunes y manifiestas en el sujeto místico se estaría diciendo que las experiencias místicas solo son posibles en aquellas personas que han vivido esos epifenómenos físicos o estados alterados de conciencia. Y, no es poco común identificar experiencias de Dios con manifestaciones ya sea psíquicas o físicas, precisamente porque tienen como sello de garantía el ir acompañadas de múltiples «fenómenos extraordinarios» ${ }^{22}$. Es-

${ }^{21}$ Martín Velasco. J., Introducción a la fenomenología de la religión., op. cit., p. 164.

22 Con este término, el autor del fenómeno místico designa las múltiples formas de experiencia que vive el sujeto místico independientemente de su pertenencia a una tradición religiosa o a contextos profanos: experiencias de levitación, visiones, audiciones, presencia de estigmas, anorexia mística, fenómenos físicos y estados alterados de conciencia. Si bien es verdad que los «fenómenos extraordinarios» con mucha frecuencia acompañan la 
to nos llevaría a la idea de un tipo de predilección de Dios, o de un más allá del Universo, para que solo un pequeño grupo de humanos alcance «esas cimas de la historia de las religiones que son los místicos ${ }^{23}$. En realidad, estos fenómenos son propiamente accidentales y secundarios.

Si bien es verdad que la forma de lenguaje en los escritos de los místicos suele ser atractiva para quien intenta vivirlos o quiere estudiar los hechos que transmiten, su mala comprensión deformaría la experiencia que ellos mismos quieren comunicar: el carácter absoluto y trascendente del Misterio y la implicación existencial con dicha Trascendencia. Dos inclinaciones igualmente peligrosas: o se deja de aspirar y anhelar el Bien, la Verdad y el Amor — que no es accesible ni universal, a menos que la Gracia lo conceda ${ }^{24}-\mathrm{o}$, provoca tal atractivo, que el sujeto invierte indebidamente los fines y los medios en función de su autorrealización. Es evidente que ambas situaciones son causa de grandes males y lo opuesto de la vida mística: la barbarie.

Tenemos pues, que hay concepciones sobre la mística que se alejan por completo de su núcleo esencial. Ante los posibles desvíos para comprender la mística a partir de las experiencias extraordinarias, habrá que incursionar alguna vía que nos ayude a comprender esta máxima forma de realización humana.

La estructura relacional del hombre y ciertas experiencias en su trayecto existencial configuran su identidad y lo preparan para otras experiencias plenas $^{25}$. Seguimos en diálogo con ambos autores, así que, desvinculamos la relación religiosa como sentimiento de dependencia absoluta o, de un saber racional, para situarla en la actitud fundamental libre del sujeto y su fundamento ético. Para García-Baró ir a las formas previas, esencialmente anteriores de religión, es la vía más adecuada y no tanto la «relación interpersonal mediada por la ética» ${ }^{26}$.

En la última parte de este artículo recuperaremos las siguientes ideas para ensayar lo que García-Baró, con gran originalidad, trae a la reflexión fenomenológica: la experiencia primitiva del misterio y su carácter de absoluta ${ }^{27}$. Los misterios rompen drásticamente con la rutina del mundo, vaciarán de sentido y

experiencia del místico, el estudio comparado del fenómeno místico realizado por Martín Velasco ha ayudado a comprender que la relación con el Misterio tiene una estructura que subyace a las experiencias con las que el sujeto interpreta lo vivido. Frente a este fenómeno la actitud razonable requiere toda una serie de cautelas teológicas, epistemológicas y científicas. «Los rasgos extraños, pintorescos y hasta ridículos que rodean algunos fenómenos extraordinarios bastan para desacreditarlos y privarles de toda credibilidad como testimonios y manifestaciones de una auténtica vida mística», Martín Velasco, J., El fenómeno místico. Estudio comparado (Madrid, Trotta, 1999), p. 49; pp. 75 ss.

23 Ibid. p. 10.

24 Señalamos que esto no supone pensar que anulamos o relativizamos la acción de la Gracia.

25 Cf. García-Baró, M., Del dolor, la verdad y el bien, Salamanca, Sígueme, 2006, p. 208.

26 GARCía-BARó, M., «Aproximación con temor reverencial a la esencia de la religión» en: AA. VV. Tomo 105, Sal Terrae (2017) p. 972

27 Ibíd. pp. 65-247. 
expectativas, pero también, exceden de sentido, abren posibilidades, aumentan confianza, abandono y anhelo humilde de más verdad. Con ello, recuperamos el anhelo de libertad respecto de todo lo mundanal, precisamente para experimentar que la relación ética interpersonal, es de otro modo que ser (Levinas) ${ }^{28}$.

\section{LO ABSOLUTO COMO MEDIACIÓN Y PURIFICACIÓN DE LO PROPIAMENTE RELIGIOSO}

Para Rudolf Otto, aún influido por Schleiermacher, la experiencia de absoluto sigue estando en la esfera del sentimiento, y solo ulteriormente se pasa a un nivel racional que explica o esclarece dicha experiencia ${ }^{29}$. Lo que queda claro es que sentimiento y razón no pueden identificarse con lo santo si entendemos que lo santo es lo absolutamente Otro:

«El peligro acecha en todas las mediaciones, desde los más puros conceptos a las más rudas representaciones, pero puede ser designado con un nombre común. Estaríamos peligrosamente en la idolatría, que designa la confusión del Misterio con sus mediaciones y el intento por dominarlo mediante el dominio de estas últimas. Para luchar contra este peligro los hombres verdaderamente religiosos, los grandes reformadores, los profetas, predicarán la supresión de las imágenes, la negación incluso de los conceptos más elevados de la teología, la eliminación de los ritos más consagrados y el retorno a un reconocimiento del Misterio en toda su pureza ${ }^{30}$.

Lo santo pertenece a una realidad Otra y el eco subjetivo personal y absolutamente incondicional es perfecto en su clase, "hic et nunc». Si lo santo es distinto de lo sagrado es porque se identifica con una realidad última que determina un nuevo orden, lo contextual y todos los elementos periféricos y relativos $^{31}$. Por eso, dice Martín Velasco, es imprescindible la distinción entre mediaciones de lo sagrado y lo santo mismo. De esta forma se salvaguarda la absoluta trascendencia de Dios y se radicaliza el carácter de la mediación ética para hablar de religión ${ }^{32}$. En consecuencia, se salva a la religión de cualquier superstición o deleite sagrado, consolador, o estético.

Sobre estas bases, tomamos la vía filosófica de base fenomenológica. Según García-Baró se puede explicar que hay modos de estar en la verdad a partir de

$28 \quad$ Ibid. p. 105.

29 Rudolf Otto abre una vía que pone en evidencia las dificultades que se tienen cuando se intenta una definición de lo santo. La sugerencia está en levantar la cuestión ¿qué siento cuando me relaciono con lo santo? Es posible describir lo que me pasa a mí, sujeto individual, cuando estoy ante lo santo. Así que, describo lo que provoca, eco subjetivo, pero no quién o qué es lo santo. Según las descripciones del, el eco subjetivo que provoca la realidad se explicaría con los adjetivos de realidad tremenda y fascinante. Como ya se ve, ambos rasgos hacen referencia a afectos ambivalentes.

30 Martín Velasco, J., Introducción a la fenomenología de la religión., op. cit., p. 206.

31 Cf. Ibíd. pp. 130-130.

32 Acerca de este mismo tema, $c f$. García Guerrero, B., La relación religiosa en la obra de Emmanuel Levinas, Universidad Pontificia de Salamanca, 2016, pp. 305-331. 
nuestro habitar la realidad. Empezamos por decir que nuestra estancia en la vida es dinamismo vital y sentido abierto a la realidad sobreabundante - tanto por sus desgracias y horrores, como por sus maravillosas liberaciones y gozos. Asimismo, la realidad -incluido yo- recibe multitud de experiencias de algo absoluto. Un hombre abierto siempre puede ser violentado por el mundo de angustias, preocupaciones, problemas y males, y según se avance, serán las primeras noticias de lo absoluto. Por esto mismo hay que precisar que el encuentro con lo que podemos llamar legítimamente absoluto, no es ni solo, ni primordialmente Dios, sino algún acontecimiento intramundano, que solo posteriormente, podrá interpretarse como huella de lo divino Absoluto ${ }^{33}$. Como se puede inferir, la experiencia religiosa debe mantenerse al margen de lo relativo para evitar convertirla en idolatría o superstición con la que se pueda confundir.

Hasta aquí, el diálogo que establecemos entre las perspectivas de Martín Velasco y García-Baró puede concluir que la mediación de lo absoluto, su búsqueda y su venida, provoca la respuesta incondicional por parte del hombre que - sin duda - debemos incluir para un acceso adecuado y de sinceridad religiosa. Por paradójico que parezca, siempre es un peligro definir la religión como «sentimiento de dependencia absoluta» (Schleiermacher), aún cuando se nombren sentimientos absolutos y desligados de una relación que el sujeto pueda dominar.

Una mirada no superficial estaría de acuerdo en, que si hay relación religiosa, hay que indicar que se tiene, de alguna manera, relación con lo absoluto sin descartar que la experiencia de la Presencia inobjetiva del Misterio - en su absoluta trascendencia o inmanencia- pueda consistir en experiencia de algo del mundo, de algún objeto o paisaje, o de alguna facultad humana. Pero sobre esta validez: ¿Cómo decir que cualquier relación con la Realidad última puede ser análoga, incluso a alguien tan parecido como lo es nuestro prójimo? En esta dirección, como veremos, según García-Baró el problema se ve bien al afrontar el encuentro intersubjetivo como la categoría que mejor simboliza la relación religiosa, que aunque no la agota, sí la incluye ${ }^{34}$.

Si bien, es un esfuerzo filosófico prometedor para el estudio de la mística, el uso de la relación interpersonal como lo hizo M. Buber, y de mejor modo Martín Velasco en su excelente descripción del encuentro con Dios ${ }^{35}$, elegir la empatía intersubjetiva cómo instrumento hermenéutico para explicar la relación religiosa se vuelve problemática.

33 Cf. García-Baró, M., «Notas sobre el centro del ser humano y su capacidad de Dios»: M. I. Rodríguez Fernández (dir.), Consciencia e interioridad. Ávila, CITeS, 2018, p. 27.

34 Cf. Martín Velasco, J., op. cit., pp. 33 ss; 278 ss

$35 C f$. García-Baró, M., "Más yo que yo mismo». Un ensayo en los fundamentos de la filosofía de la mística"; Martín Velasco, J., La experiencia mística. Estudio interdisciplinar. Madrid, Trotta, 2004, pp. 287-289 
García-Baró presenta tres razones principales ${ }^{36}$. Hay una distancia insalvable entre el yo respecto del tú, será precisamente esto lo que nos auxilia para hablar de alteridad radical ante el otro. Justo lo que hace que el otro sea otro es que ninguna vivencia emigra de uno a otro — «cada vivencia de los demás encierra un misterio». Pero también es verdaderamente cierto que él y yo compartimos zonas de personas semejantes. Pues bien, veamos la siguiente consideración: si Dios, que asiste a mí creación, me conoce, me escruta y nada de mí le es oculto, «Dios no puede ser concebido con ignorancias ni distancias [...] respecto del fondo real de las existencias que Él ha creado» ${ }^{37}$, por tanto, Dios no es precisamente empático respecto de esas distancias que sí se respetan escrupulosamente entre los humanos. De esto se sigue la dificultad para defender hasta el final que la relación intersubjetiva puede ser análoga a la relación con Dios.

Necesitamos un hilo de sentido que nos permita descartar, como insinuamos antes, que la experiencia de Dios pueda consistir en experiencia finita, la experiencia de alguna cosa, objeto, paisaje o incluso de cualquier analogía muy próxima a Él, como soy yo mismo, que sé con todo el énfasis del mundo que no soy $\operatorname{Dios}^{38}$.

Tal como lo mencionamos al principio de este artículo, la cuarta y quinta navegación filosófica piensan lo absoluto como objeto de comportamientos originales perceptivos, secretos y misteriosos. «La experiencia religiosa [...] es experiencia de lo absoluto» ${ }^{39}$, pero la experiencia del absoluto es, a la vez, experiencia de un enigma y «el enigma abre al hombre a todos los vientos de todas las posibilidades $»^{40}$. Así pues, plantear el problema cuidadosamente debe abordar las experiencias de absoluto y dar paso a la primacía viva de los misterios en la vida de un sujeto ${ }^{41}$.

Podemos decir con evidencia que la verdad primordial es entender la vida como absoluta, por ejemplo, es imposible fingir que estamos vivos. Ahora bien, la vida no solo se alimenta de ella misma sino también de sentido (enigmas y misterios), de todo aquello que no soy yo y que puede ser vivible, comprensible

$36 \quad$ Ibid., pp. 42-45.

37 García-Baró, M., De estética y mística., op. cit., p. 44.

38 No se debe olvidar que la experiencia mística, por ser experiencia originaria del fondo último de nosotros mismos, siempre peligra con el amor a uno mismo o a lo sagrado de la vida.

39 Ibíd., p. 46.

$40 \quad$ Ibid., p. 49.

41 «Por ejemplo, la Revelación supone la existencia en sí del tiempo, pero no contiene una teoría filosófica acerca de él; supone la existencia en sí de sujetos que pueden alcanzar la salvación, pero no desarrolla una antropología filosófica ni una teoría de la intersubjetividad; supone la idea de ser, pero no contiene un tratado de metafísica general; supone el carácter esencialmente adecuado de las palabras humanas para la comunicación de muchas de las cosas supremas, pero de ningún modo se ha detenido en elaborar la filosofía del lenguaje. Y, sin embargo, ¿cómo podría caber la pretensión de haber ni siquiera intentado responder al don divino, si no se procura penetrar intelectualmente todo lo que él ofrece?». Cf. Ensayos sobre lo Absoluto, Madrid, Caparrós, 1993, p. 24. 
y trasladarme a más sentido. El sentido dilata la vida misma y el sentido crece gracias a la vida ${ }^{42}$. Por esto mismo se puede adorar «la misteriosa riqueza del sentido y la vida en el primer momento en que ya se nos presentan ${ }^{43}$. Bajo estos presupuestos ies posible pensar que no estén dadas las condiciones para que cualquier hombre que lo desee pueda llevar a cabo el destino de su conocimiento de la realidad y su responsabilidad personal?

Consideremos al sujeto y su lado objetivo. Decir sujeto es decir actos, acciones, actitudes y proyectos de vida en los que ella se pregunta, sufre, comprende, goza y se angustia. Pues bien, este lado subjetivo está enfrentado con el lado objetivo que llamamos sentido - en una parte enigmático y otra evidente ${ }^{44}$. Pero el contenido de lo real de la vida tiene un centro: el misterio. Ahí se encuentran mundo, historia, naturaleza, seres ideales, potencias sagradas, lo santo y todo lo que el yo-sujeto pueda descubrir gracias a su libertad y razón ${ }^{45}$. En efecto, no le es posible a ninguna existencia subjetiva evitar este enfrentamiento con lo real.

Dentro de este marco podemos concluir que la tarea del sujeto es la actitud descentrada para aprender, tanto de sí mismo - preguntarse, sentir, atender más, discernir - como de lo que no es yo, y que aparece como misterio tremendo y fascinante (Otto). Podemos decir así, que se descubre la expresividad de Dios en el radical silencio de mí mismo y en la alteridad de mi yo, máxima distancia y absoluta trascendencia: presencia inobjetiva de la más absoluta Trascendencia en la raíz de todo lo real y en el corazón de la persona, dirá Martín Velasco.

Llegados hasta aquí queda saber cómo surge la experiencia de lo absoluto; ¿se trata de una experiencia concreta o, de un imperativo categórico? ¿un hombre se toma la vida y sentido en serio gracias a los acontecimientos providenciales de la vida? ¿acontece por una desafortunada experiencia personal?

Si lo absoluto es objeto de la existencia y objeto de comportamientos originales se pueden sacar dos conclusiones: (a) saber que estoy vivo y que tengo problemas, es experiencia absoluta; (b) el absoluto deber de seguir viviendo embarcado y libre en la corriente imparable de las acciones - ante las cuales soy máximamente responsable-, es experiencia absoluta.

Como es evidente, situados aquí es imposible ser escéptico, y quien lo pretenda, estaría justificando un punto crucial: relativizar el mal. Estas alusiones

42 Cf. García-Baró, M., La filosofía como sábado, Madrid, PPC, 2016, p. 27.

43 Ibid. p. 54.

44 Distinguimos realidad de mundo porque el término mundo ya sugiere una especie de coseidad, de no vida, de algo ajeno y opuesto al yo. Precisamente, dice García-Baró, la hazaña de la fenomenología de Husserl ha sido mantenerse en la estricta pre-mundanidad de la fenomenología. Hay un ámbito donde se juega el problema de la verdad que sería previo a la subjetividad respecto de las cosas mismas. Cf. GARCÍA-BARó, M., Vida y mundo., op. cit., p. 114.

45 Cf. García-Baró, M., De estética y mística., op. cit., p. 254-265. Vivir desde una actitud religiosa lograda significaría reaccionar ante lo real de la vida, reconociendo en ella los misterios y sus formas sagradas y, sobre todo y lo más estrictamente religioso que es lo santo. El mundo, lo visible, la superficie de la vida objetiva, están siempre desgajándose de la vida subjetiva, de lo invisible, de la noche real, donde habita solo el gozo, aunque al lado del dolor. 
dan idea a la quinta forma de navegación filosófica para pensar lo religioso confrontando racional y radicalmente el mal. De esta forma nos oponemos a aquellos pensamientos antifilosóficos que piensan que el mal es justificable, o que puede robar una pizca de sentido. Lo absoluto se rebela ante ese extraño acto humano que es el uso desviado de la libertad: el mal radical. «La maldad no viene al hombre desde fuera, sino que procede de dentro a fuera. Evitarla en lo posible es la primera tarea del pensamiento. Primado de la razón práctica, dirá dos milenios después de Sócrates, Kant» ${ }^{46}$. Pues bien, «sin el conocimiento de lo absoluto no hay crítica absoluta de lo relativo» ${ }^{47}$, y para ello la razón teórica y práctica es decisiva.

Si el hombre no puede ni conocer, ni desear, ni tener nostalgia de una realidad absolutamente trascendente ¿por qué se puede decir que los misterios proceden de algo análogo a un llamado personal, a Dios — divino Silencio-, y no a la oscuridad impersonal, a un vacío o a la nada ${ }^{48}$ ? O, ¿cómo se puede explicar una hipersubjetividad irrepresentable que habita el fondo de todo lo real, que mueve los posos profundos de mi alma, y que es el fundamento de la trascendencia que nos envía los misterios?

Cuando el ser humano vive un misterio como el enigma de estar existiendo, saberse mortal y verse lanzado sin preparación a un tiempo y cultura no elegidos, no hay por qué pensar que es la nada impersonal la que le ha introducido en esa situación. Pero tampoco tenemos por qué decir tan apresuradamente que es precisamente Dios quien nos puso en tal situación. Recordemos que la ruptura de toda representación de lo divino es el antídoto para evitar el ídolo y toda fácil concepción de un dios fabricado a la medida del hombre.

Si queremos decir que la Presencia de Dios fundamenta la realidad y el centro mismo de la vida humana, tenemos que conservar la idea de que ésta no es de condición objetiva ni susceptible de experiencia objetivable que podamos explicar con simplicidad. Lo que sí podemos decir es que hemos sido alterados, y que (por alguna sabiduría) básica hemos decidido seguir viviendo, hemos querido buscar respuestas y sentido y hemos esperado, pero ¿por Quién? o ¿a Quién? El ser humano es un ser-a-la-espera y no un «ser para la muerte». En palabras de García-Baró:

«En el hombre interior habita la verdad, y la empresa de querer evadirse de sí mismo es locura y sinsentido, porque hasta para intentar concebirla hay que plegarse a las leyes absolutas del sentido, a la razón que me habla como un yo mismo que mi yo empírico, falible, desanimado y poco enérgico, muchas veces desconoce» ${ }^{49}$.

46 García-Baró, M., Sócrates y herederos., op. cit., pp. 21-22.

47 Ibid., p. 22.

48 Podríamos lamentar el haber nacido porque se nos mete en un misterio que hemos de cargar de por vida. Pero si la firmeza del suelo ha desaparecido y los soportes se resquebrajan, siempre está nuestra libertad para decidir que hacer ante ellos.

49 García-Baró, M., La compasión y la catástrofe. Ensayos de pensamiento judío, Salamanca, Sígueme, 2007, p. 216. 
Hay que señalar que somos una tensión trascendente que puede ser trascendida desde fuera de ella misma. Dios — en el fondo de toda realidad — es huella de trascendencia irrepresentable, inimaginable, pero es presencia inobjetiva y activa que capacita para lo infinito, para lo imposible. «La autonomía y la consistencia que Dios mismo confiere a lo creado, hace posible y necesario el amor del hombre a lo creado, a los otros hombres y a sí mismo, sin que ninguno sea «objeto» del amor humano que puedan ser suplidos, sustituidos o «colisionados» por el amor de Dios» ${ }^{50}$.

El amor a Dios y el amor al próximo se sitúan en un orden de realidad diferente, es así como, no se puede decir que el amor de Dios permite que el hombre ame otras realidades, a otras personas, no como en sí mismas sino como sustitutos o mediaciones de Dios. En temas de mística, siempre es importante recordar aquella formula de humanidad de Kant, según la cual el hombre es un fin en sí mismo y no un medio para que yo tenga lugar exclusivo con Dios. Pero no menos necesario e importante es el énfasis de Teresa de Jesús en advertir el criterio de verdad en el amor a Dios:

«Nos pide el Señor: amor de Su Majestad y del prójimo, es en lo que hemos de trabajar. [...] La más cierta señal que, a mi parecer, hay de si guardamos estas dos cosas, es guardando bien la del amor del prójimo; porque si amamos a Dios no se puede saber, aunque hay indicios grandes para entender que le amamos; mas el amor del prójimo, sí» ${ }^{51}$.

$\mathrm{El}$ amor no sustituye sino fundamenta. La trascendencia del amor reconoce y mantiene su alteridad constitutiva para hacerse posible. A Dios se le conoce amando.

Llevados por García-Baró a Rosenzweig y a Levinas encontramos alguna luz para nuestra reflexión. "La apertura del yo amo, del yo conozco, del yo estoy en el mundo, es en principio, "la capacidad de relacionarse con todo" desde la diferencia ${ }^{52}$. Siempre que se dice yo, hay un amor origen que lo precede todo. Por tanto, el amor humano es ya el amor de alguien amado primero ${ }^{53}$. La conciencia despertada lleva como un retraso. Si el yo es amado primero, ya no le es posible hacer oídos sordos. Ahora ya, ninguna puerta queda cerrada ${ }^{54}$. Pero semejante presencia abre puertas por dentro y por fuera de nosotros mismos. El yo singular es escucha obediencial requerida en cada momento. Siempre actúo, siempre estoy sintiéndome; estoy híper-ligado — en el sentido de Zubiri-a un fondo, pero como ser separado soy libre, y tengo esta condición. La estructura dialéctica de la presencia puede ser percibida como voz que avisa que la

\footnotetext{
50 Martín Velasco, J., La experiencia cristiana de Dios, Madrid, Trotta, 5ª 2007, p. 207.

51 Santa Teresa de Jesús, Quintas Moradas 3,7-8. (Obras completas, Burgos, Ed. Espiritualidad, ${ }^{52000)}$.

52 García-Baró, M., op. cit., p. 266.

53 Ibíd., p. 266.

54 Ibid., p. 268.
} 
vida tiene más de un sentido misterioso. Y, la voz en mí, aun más misteriosa me reitera: esto que vives no es lo último ni lo definitivo. ¡Sigue, vive, ve, camina!

La muerte misma puede ser la experiencia de la nada, o la fuerza que empuja a seguir viviendo, sin saber cómo, pero por eso mismo queda inaugurada mi confianza y mi paciencia. Quienes se interesan primero por el misterio de la realidad que les hizo conocer la muerte, o sea, que hay posibilidades, se interesan más apasionadamente por los misterios de la realidad que les revela el $\operatorname{amor}^{55}$.

En definitiva, cuando se habla en religión de mandatos y sacralidades sin experiencia personal ${ }^{56}$ muy bien pueden ser experiencias de sustitución religiosa que enturbian y pervierten la actitud fundamental. En lugar de dar paso a la vida mística, la clausuran. En la vida mística todo es probado por la experiencia y la tentación máxima en estos temas es la lamentable caída en la peor de las religiones: encerrarnos en nuestro narcisismo por miedo a la verdad.

\section{El CENTRO PERSONAL NO ES QUIETISMO NI INTIMISMO}

Empecemos ahora por considerar una expresión frecuente en los místicos: la metáfora del centro del alma. Si el místico es quien lleva a su realización plena la religión, cuánto más el elemento moral, que se presenta como un ejercicio radical. Es mentira que la vida mística sea pura pasividad; «los que se vean llamados de una manera muy especial a vivir en la intimidad del misterio divino deben ser los hombres más abiertos, más probados, más expuestos a la realidad y que más hayan analizado las raíces de su propia existencia ${ }^{57}$. San Juan de la Cruz llega a decir: «no esperes al gusto, obra virtud que bástate la razón ${ }^{58}$. Es del todo imprescindible decir que religión sin ética, es decir, sin práctica, puede ser una peligrosa religión: recrear, en nombre de Dios, un ídolo de nosotros mismos.

Pues bien, en fenomenología «no cabe ninguna ontología sin base ética, dado que ninguna pregunta es ni más urgente ni más amplia que la que se interroga por el bien, por el modo como debe vivir el hombre» ${ }^{59}$. Por más que se quiera polemizar sobre la relación entre mística y filosofía, será inevitable reconocer su punto de convergencia: la responsabilidad individual por la verdad que cristaliza en un modo de vivir. Esto nos lleva a pensar que una conciencia transformada implica un lado práctico y un lado social, tal como se inscribe

55 Cf. García-Baró, M., Aproximación con temor reverencial a la esencia de la religión, «Elogio de la religión», Sal Terrae, Vol. 105 (2017) p. 978.

56 La filosofía es un programa existencial de lucidez radical. Comprueba sin concesiones ni sentimentalismos, sin ninguna falsa piedad, qué valen realmente las opiniones que has hecho tuyas.

57 Ibid., p. 238.

58 SAn JuAn de la Cruz, Dichos de luz y amor, 19.

59 García-Baró, M., Sócrates y herederos., op. cit., p. 121. 
en religión el desarrollo de la fe. La actitud fundamental que constatamos al analizar la relación religiosa, tiene una génesis, amar es su ejercicio, y no tanto una realización puntual. En cada instante la condición humana cuenta con una especie de libertad extraña que le permite soltar prejuicios existenciales, e incluso espirituales, mientras se avanza, pero esto lo hace dolorosa o deliciosamente. Dolorosa porque no le es gloriosa, pues antes la pone miserable y amarga la luz que le da el propio conocimiento ${ }^{60}$. Y deliciosamente porque hay un punto de liberación en el que esa luz ya no es esquiva (Juan de la Cruz); el misterio se dona en exceso pero siempre reclamando más atención y sabiduría.

Ya se ve, que la inseparabilidad entre ética y religión, ocupan un lugar central para los autores que tratamos. Coinciden en decir vigorosamente que cualquier hecho religioso está situado en una posición claramente ética absolutamente necesaria:

«Una religión sin [ética], ya no es una religión posible para nosotros, sino mera superstición romántica. Y esto no ha de ser apresuradamente entendido como un síntoma letal de etnocentrismo. Más bien es la confesión palmaria de que las diferencias culturales profundas trazan fronteras y hasta grietas muy hondas en lo compacto de la humanidad del hombre ${ }^{61}$.

Como constatamos, es una necesidad la de cimentar una articulación correcta del elemento ético y religioso. Los problemas fundamentales en el estudio de la mística frecuéntenme radican en la interpretación de que una esfera esté por encima de la otra. En la esfera de lo ético lo religioso no es una región superpuesta, sino un ámbito propio de su esencia.

Si en el sujeto religioso se cumple un ejercicio dinámico de anhelo de verdad, de amor al Bien y de apertura al Misterio, se puede retroceder y pensar una experiencia que lleve incoadas otras experiencias culminantes como la ética, intersubjetiva y religiosa. Dicho esto, tomamos en cuenta que el trabajo fenomenológico debe analizar con sumo cuidado cada tipo irreductible de las experiencias originarias desde su lado subjetivo y objetivo. Por un lado, el cuidado de las cosas y de su verdad, y por otro, venerar la esencia del hombre.

La actividad subjetiva en lo más interior es un elemento esencial en el acercamiento a la mística, por esto recuperamos el concepto de acontecimiento, misterio ${ }^{62}$ y mal. Concretamente, la experiencia de alteridad radical del misterio en sus múltiples formas de presentarse y la actitud que provoca recupera los fundamentos ético y filosófico de la Vida del místico (el yo secreto y más yo que yo) como ens capax Dei: memoria Dei, intelligentia Dei y el bien como amor $D e i^{63}$.

En resumen, la filosofía en la que nos sumergimos trata de pensar la conversión del corazón como una actitud radical moral, pero referida a un

60 SAN JUAN DE LA CRUZ, Llama de amor viva B 1,19.

61 García-Baró, M., Del dolor, la verdad y el bien., op. cit., p. 175.

62 Conceptos profundamente tratados por Levinas y Gabriel Marcel.

63 Cf. García-Baró, M., De estética y mística., op. cit., p. 220. 
acontecimiento misterioso universal que nos ha sucedido a todos. Motivo por el cual García-Baró afirmará que ningún hombre puede vivir solo en la superficie. Como veremos más adelante, la experiencia ontológica deja «secuelas imborrables» que nos recuerdan que hay un fondo esencial en nosotros mismos (aunque es verdad que podemos conseguir un olvido eficaz de éste, nunca es eliminable del todo $)^{64}$. Esta idea sumamente interesante y novedosa no parte, ni de las tormentas que nos envía la Providencia en la edad adulta - como nos lo explicó san Agustín-, ni de grandes revelaciones para ir a los niveles de profundidad moral que supone la vida mística; sino que, de algún modo ya siempre están presentes.

\section{El sentido de existir ante Aquel que viene}

Es muy cierto que el hombre está llamado a desarrollarse en la historia y el encuentro interhumano es la experiencia que exagera el sentido de lo que hasta ese momento hemos descubierto. En éste aflora la consciencia de una realidad misteriosa: un tú humano. La matriz simbólica que seguíamos con Martín Velasco, con García-Baró integra la síntesis de respectividad afectante y alteridad absoluta del otro como algo muy peculiar que subyace a todas las formas de vivencia de relación religiosa. Según sea el grado de perfección de la síntesis de intimidad y alteridad ante su presencia, tendremos el criterio para medir el grado de perfección de cualquier forma religiosa. La degeneración de un aspecto de esta síntesis, es decir, si se afirma una a expensas de la otra, terminaría por comprometer la experiencia de lo divino.

Los fundamentos éticos y filosóficos de la vida mística por ser impulso y alteridad van de acción en acción anhelando que el Bien triunfe, pero las vivencias éticas son experiencias originarias plenas que están entrelazadas inevitablemente con un modo peculiar de presencialidad que el místico nos comparte: de saber práctico y metafísico, de lo bueno y lo verdadero más íntimo que nuestra intimidad y más allá de lo trascendente.

¿Cómo interpretar la experiencia que eleva a los místicos a un amor tan calificado, atendiendo a la experiencia originaria que la hace posible y que llamamos misteriofanía? ${ }^{65}$.

Para responder, iremos de la mano de García-Baró. Centramos la atención en aquella experiencia que acontece fundamentalmente en la infancia y que

64 Cf. Ibíd., p. 239.

${ }_{65}$ M. García-Baró ha reivindicación la infancia en la filosofía basándose en las experiencias originarias y la misteriofanía como experiencia fundamental que se puede llevar a conceptos de verdad y de bien. Esta «ha sido descalificada por el pensamiento moderno como época de irracionalidad y falta de lucidez». Véase la descripción pormenorizada que el autor dedica a este tema desde su punto de vista, esencialmente filosófico, en el capítulo "La infancia, el silencio y las experiencias culminantes», en: Del dolor, la verdad y el bien, pp. 65-79. 
tiene especial relevancia a la hora de buscar el origen de la vida que decimos mística. Se trata de lo que llamaremos experiencia matriz.

Primero hay que decir que toda experiencia es primordialmente afectiva y, para la filosofía, el afecto es la primera forma del pensamiento. Es un hecho que la experiencia mística es el despliegue de las experiencias originarias plenas ética y filosófica, pero a su vez de una experiencia originaria excesivamente misteriosa. Para explicar cómo llegamos a estas conclusiones, hemos de retroceder y buscar la primitiva experiencia del misterio en el orden de nuestro descubrimiento. «Mientras la muerte y el amor no se acercan al hombre, la historia de su bondad y su búsqueda de Dios no puede decirse que haya empezado ${ }^{66}$.

Todos hemos sabido que hay un final, que moriremos y que el tiempo que tenemos es limitado e irreversible. En ese momento la vida es perturbada por la noticia, excesivamente misteriosa de la muerte, un dilema sin solución: no quiero morir, pero a la vez no quiero vivir como estoy viviendo. El nombre para esta experiencia originaria es el de experiencia matriz y es inolvidable. Por eso, acentuará García-Baró, en ella somos, nos movemos y existimos. El ímpetu y luz que provocó le otorga el rango de protoexperiencia ética y religiosa, es su germen siempre latente.

El acercamiento fenomenológico a la experiencia matriz se pregunta por lo que es exactamente esa luz y actitud provocada y, por qué se puede considerar como la experiencia primitiva de un amor transformado y calificado como el que describen los místicos: ya acción que no puede dejar de oír la voz inspiradora del Bien como amor, siempre presente.

El primer rasgo que retomamos de esta experiencia es la de su intensidad afectiva. La llegada del primer misterio, por principio inesperado, de algo que no domino sino me domina a mí, se vive como tremendo, violento y sobrecogedor. Con el debido matiz, vemos un paralelismo con el comentario de san Juan de la Cruz en el libro de Llama: Dios se ha hecho cruel contra ella y desabrido ${ }^{67}$. En medio de tantas cosas, nos vienen noticias de muerte: la abuela, un hermano, el perro, el pajarito...

Todos hemos sabido que la vida actual —en la que se vive tan suavemente acción tras acción obteniendo lo que se quiere- que se comenzaba a gozar por lo que tiene de dicha, acabará también. Ahora bien, la solución adoptada es sabiduría primigenia básica: ignoramos como vivir pero queremos vivir. Sin mucha orientación y con profunda congoja la muerte se torna excesivamente desconocida y la vida es solo preguntas sin respuesta. Como no se sabe mucho más, nos hacemos aliados del tiempo, pero además, ha habido una acción decisiva - por cierto, esencial en la vida de los místicos—, la acción de vivir, confiar y esperar. ¿No es esto ya sabiduría?

66 «Señales de lo absoluto en el trayecto de la vida». G. Tejeiras (coord.), Experiencias del mundo, misterio de Dios. Salamanca, Universidad Pontificia de Salamanca, 2015, p. 48.

67 San Juan de la Cruz, Llama de amor vida B 1, 20. Obras completas, Madrid, Ed. Espiritualidad, ${ }^{6} 2009$. 
La vida nos está forzando siempre a tomar decisiones, es como si nos iniciara constantemente a lo nuevo, y Dios es novedad absoluta. Lo que nos preserva de los hábitos rutinarios, a pesar de nuestra intranquilidad, ha tenido un inicio con la experiencia matriz.

La segunda lección que recibimos de la experiencia matriz tiene que ver con dos rasgos esenciales del misterio: un misterio ni se olvida nunca, ni tiene solución con ninguna ciencia o técnica. La llegada del primer misterio en la infancia hizo su morada y se hizo habitante para siempre dejándonos inquietos de por vida. Su enseñanza primordial ha sido que nos sabemos amenazados por lo desconocido aunque también siempre se avecina una experiencia maravillosa. El caso es que sufrimos porque no sabemos qué queremos y nos angustia ignorarlo. El no querer morir, pero tampoco querer vivir en la misma situación para siempre ${ }^{68}$, son alternativas aparentemente insufribles e imposibles. Por una parte, una experiencia en la que el tiempo es limitado y por otra, un yo solo que sin saber casi nada se ve confundido y confrontado con una realidad que le desborda. Ahora bien, hay una única alternativa posible -y es ciertísimo que todos la tomamos - ¡decidimos vivir! (algo o alguien nos empuja). Como se ve ya «el misterio nos ha de acompañar ya siempre, pero no siempre de la misma manera ni mostrándonos el mismo rostro» ${ }^{69}$.

Pues bien, haber hecho semejante experiencia nos ha descubierto que somos alguien que no se contenta con lo que hay, si sufrimos es que lo rebasamos todo y si queremos vivir de una manera diferente es que llevamos en nosotros una profundidad inconmensurable. De esto se concluye que, más acá de nosotros están las respuestas al enigma de la existencia pero también más allá de nosotros está aquello que nos impulsa a una plenitud, de momento, excesivamente desconocida.

Por lo dicho anteriormente, la experiencia matriz es el germen del abanico pluriexperiencial humano que constituye una sabiduría básica para la llegada de más misterios. Esta es la estructura de relación que buscamos para constatar que Dios nos inicia en la vida presentándonos sus riquezas insondables. Con tensión, sí, pero nos ha dado la condición para descubrirlas. De esto tenemos una bella explicación en las primeras moradas de Teresa de Jesús: «considerar nuestra alma como un castillo todo de un diamante o muy claro cristal adonde hay muchos aposentos, así como en el cielo hay muchas moradas ${ }^{70}$.

Es muy común pensar que las experiencias originarias ética, filosófica y mística se dan en la vida adulta dada su importancia y la madurez que exigen de la persona. Sin embargo, como hemos visto, a muy temprana edad ha habido esa experiencia fundante inolvidable, aunque sí adormecible por nosotros

68 «El fondo de esta congoja no es, sin embargo, esta conciencia de completa contingencia y, al parecer, de insignificancia, sino acaba por ver que aún sería por que no hubiera muerte y la vida se nos extendiera sin fin». GARcíA-BARó, M., La metafísica y la prudencia, Discurso de recepción Real Academia de Ciencias Morales y Políticas, Madrid, 2019, p. 40.

69 Ibid., p. 42.

70 Santa Teresa de Jesús, Primeras Moradas $1,1$. 
mismos. Pero esta experiencia que nos dejó marcados a fuego para siempre cuando vivimos el choque con cualquier misterio, se actualiza y actualiza los recursos de nuestra situación fundamental existencial. Debe pues, quedarnos claro que solo el sujeto de aprendizaje humilde es el que recupera las lecciones de la experiencia matriz y puede descubrir con el tiempo, lo que realmente significa la experiencia de Dios. Tal como lo vio san Juan de la Cruz: «El alma enamorada es blanda, mansa, humilde y paciente».

Dando este paso García-Baró muestra que la experiencia de Dios constituye distintas formas de alteridad y de misterios en plural. Ahora nos limitamos a ofrecer tan solo algunas intuiciones.

Como ya se ve, este planteamiento ahonda no directamente en las experiencias del místico sino en la raíz antropológica de dichas experiencias. Por ejemplo, en san Juan de la Cruz, la experiencia de un amor que llamea y prueba a fuego en el más hondo del yo; una presencia que hiere siempre que estemos vivos lanzándonos a lo futuro Desconocido; certezas de saber, es decir, saber que no vivimos originariamente todo. Pero, tal vez, como lo constatamos en el místico citado, después de un largo trecho de vida, es la misma llama que delicadamente enamora. "Íntimamente traspasas la sustancia de mi alma y la cauterizas con tu glorioso ardor! Pues ya estás tan amigable que te muestras ${ }^{71}$.

Resumimos este progreso y proponemos a nuestro lector que identifique lo contenido en la experiencia matriz: a) la relación con el misterio es una relación humana con lo absoluto que toma por objeto la existencia y sus comportamientos originales; b) es relación con algo absolutamente trascendente que me introduce en la experiencia de una realidad ajena, extraña, tremenda y/o fascinante; c) el misterio descubre mi identidad con radical alteridad e individualidad hasta mostrarme el deber y respeto ante lo que yo mismo he dañado.

Volviendo a la quinta navegación filosófica, tal como se piensa lo absoluto y el mal, ahora nos servimos del concepto de misteriofanía, que como veremos, es la experiencia originaria de la presencia inobjetiva del misterio que reclama verdad y bien como amor, pero que siempre puede ser desoída o rechazada.

Tal y como hemos insinuado antes, la experiencia matriz ya vivida se va actualizando en los sucesivos acontecimientos que le sobrevienen a la persona (muerte, vida, ignorancia de lo esencial, enfermedad, fracaso, culpa, amor, perdón, etc.). Pues bien, o se enciende el alma para vivir fortalecida, desnuda y en actos de amor — un yo más yo que yo, que vive en mí- o, se queda a las puertas del castillo viviendo una vida reducida a casi nada. Puedo existir ante el misterio que viene y puedo girar, desesperar o permanecer en la superficie, eso sí, sabiendo ya siempre por experiencia bien existencial que mi hondura rebasaba la medida de todas las cosas. El misterio siempre embiste, pero es el yo libre, quien acepta o rechaza su enseñanza para seguir o interrumpir la aventura.

71 SAn JuAn de la CRUZ, Llama de amor viva B 1, 36. 
No hacen falta grandes glosas para decir que la experiencia mística, por ser experiencia originaria de nosotros mismos siempre corre el peligro de ser interpretada como el amor a nosotros mismos. Hablaremos, así, de un extravío en expresiones semejantes, tan utilizadas por los místicos, como Dios habitante del alma, en el más profundo centro. No se trata de la experiencia directa de Dios para que el yo disfrute de Él en su soledad —esto sería idolatrarnos a nosotros mismos o bien, crear un ídolo de Dios-, sino presencia en el tiempo y Aliado en el combate de la existencia ${ }^{72}$. La misteriofanía como experiencia originaria de la presencia del misterio, lo muy otro, enseña dolorosa o magníficamente: actúa y se hace escuchar, aunque su voz inspiradora casi no sea obedecida para realizarse en actos de amor.

La fenomenología de la mística lo que quiere es mostrar que hay una génesis de la actitud fundamental y una dialéctica paradójica de la alteridad del misterio tremendo y fascinante. El misterio nos aterra y nos atrae. Semejante presencia solo es venerada y vivida desde la existencia que acepta su finitud, ya vivenciada en la experiencia matriz: siempre ignoro lo esencial y ya he sido despertada para cada acción, cada decisión, cada conversación, cada oración...

Ahora bien, de acuerdo con García-Baró, decimos que la dialéctica de la misteriofanía es extraña: la experiencia originaria del mal sinsentido es algo profundamente cercano de su aparente extremo opuesto: la experiencia originaria de la presencia de sentido. En consecuencia, decir libertad es asumir que el hombre puede aceptar o rechazar la presencia del misterio hasta en lo más defendido del castillo, es decir, en el centro del alma. No se puede dudar esta verdad ante el mismo testimonio de Juan de la Cruz: «el alma de suyo es pobrísima y no tiene bien ninguno ni de qué se satisfacer, conoce y siente claramente sus miserias y pobrezas y malicia cerca de estas riquezas y bondad y deleites de la llama ${ }^{73}$. Por su parte, santa Teresa expone la misma idea ya en las sextas moradas: "dentro en el mismo palacio, que es el mismo Dios, pasan las abominaciones y maldades que hacemos los pecadores» ${ }^{74}$.

Digámoslo así, la presencia, por su sentido de alteridad, es inoportuna, interrumpe nuestra tranquilidad y provoca a nuestra pereza y olvido porque aún no sabemos vivir en actos de amor, es decir, originariamente todo. Lo cierto es que, ya hubo una actitud despertada en la infancia que tiene oídos para oír ${ }^{75}$. Pues bien, si Dios está habitante del alma y de la realidad, hay que comprender que no lo gobierna todo mientras no se acabe la vida. Lo cual, no quiere decir

72 Sobre esta cuestión quisiéramos intentar «una teoría futura en la que no es el individuo aislado quien gusta de Dios en la atracción primero y el rapto final, sino [...] el individuo acompañado, hecho ya comunidad en la casi totalidad de su existencia por el amor fecundo y la sabiduría compartida» García-BARó, M., Elementos de antropología filosófica, Morelia, Jitanjáfora Editorial, 2012, p. 81

73 SAN JUAN DE LA CRUZ, Llama de amor viva B 1, 23.

74 Santa Teresa de Jesús, Sextas Moradas 10, 3.

75 Cf. L 1, 5. 
que Dios no de noticias de su gloria eterna, solo que, «aquel que se desinteresa entre actos del juego del mundo, no goza por ello de los bienes eternos del Reino ${ }^{76}$. Hay que asumir que el ser humano, aún en el más alto grado de amor, puede perfeccionarse. Y por lo dicho de la misteriofanía, siempre pueden ser rotas todas las cosas; el sinsentido, que es mal, siempre amenaza tenazmente.

Desde este acercamiento, es claro que el yo no vive desde el principio el amor que da calor y abraza dulcemente - pero no significa que no es amor, es vida-.

Hemos llegado hasta aquí en compañía de Juan Martín Velasco y Miguel García-Baró. Nos servimos de sus palabras como síntesis y conclusión.

Para que haya auténtica experiencia religiosa se necesita ir deshaciéndose de cuanto de horrendo puedan tener los misterios que ofrecen al ser humano los enigmas del mundo y de su vida ${ }^{77}$. Por su realidad paradójica — tremenda y fascinante- tendemos a querer consuelo pero su consecuencia lamentable es que debilita la actitud fundamental, llegar a creer que no hay mal donde realmente sí lo hay o, por el contrario, que no apreciemos el bien excesivo cuando comparece ante nosotros. La presencia y radical alteridad de los misterios tal vez, como noticias de Dios y al modo de Dios liberan nuestra libertad atada a la miseria que se nos ha pegado. ¿Quién se podrá librar de los modos y términos bajos si no le levantas Tú? ${ }^{78}$.

Sabemos muy pronto y por experiencia que si hubo un misterio que arrancó algo de nuestra subjetividad y reclamó violentamente nuestro sí a la vida puede haber muchos más. Seguramente amenazarán nuestra confianza y anhelos de sentido, pero chocar con ellos es certeza de nuestra libertad, llaman a la valentía y nos descubren la fuerza del sentir y pensar, es decir, de la vida y su sentido. Es necesario comprender que la relación dialéctica con el misterio más íntimo que yo y máximamente trascendente, si progresa, nos descubre zonas y actitudes de nosotros que levantan su presencia en actos de amor. Lo más cercano, hogar donde habitamos, es lo más misterioso solo que descubrirlo nos lleva tiempo. Tal vez por esto Dios nos ha creado esperanza inquebrantable.

Con todo, sentir la vida requiere espera, pero no como acto de abandono, sino la decisión de orientar la existencia en el sentido que marca la voz del Bien como Amor.

\section{BIBLIOGRAFÍA}

García-Baró, M. (2007). De Estética y Mística. Salamanca: Sígueme.

-, (2006). Del Dolor, la Verdad y el Bien. Salamanca: Sígueme.

—, (2005). Filosofía Socrática. Salamanca: Sígueme.

76 Lacoste, J.-Y., Experiencia y Absoluto, Sígueme, Salamanca, 2010, p. 95.

77 García-Baró, M., Aproximación con temor reverencial a la esencia de la religión, «Elogio de la religión», p. 965. Sal Terrae, vol. 105 (2017) 961-978.

78 Cf. San Juan de la Cruz, Dichos de luz y amor, 26. 
-, (2007). La Compasión y la Catástrofe. Ensayos de pensamiento judío. Salamanca: Sígueme.

-, (2016). La Filosofía como sábado. Madrid: PPC, (GS).

-, (2012). Elementos de antropología filosófica. Morelia: Jitanjáfora Editorial.

-, (2009). Sócrates y herederos. Introducción a la historia de la filosofía occidental. Salamanca: Sígueme.

-, (1999). Vida y Mundo. La Práctica de la Fenomenología. Madrid: Trotta.

—, (2017). «Aproximación con temor reverencial a la esencia de la religión». Sal Terrae. Tom. 105, 961-965.

—, (2017). «Las almas, el mundo y Dios». Madrid: Universidad San Dámaso, (Subsidia 48), $35 \mathrm{pp}$.

—, (2001). «Las experiencias fundamentales» en Experiencia religiosa y ciencias humanas. Madrid: PPC, (Escrito junto con dos autores más: Carlos Domínguez Morano, Pedro Rodríguez Panizo).

—, (2004). «Más yo que yo mismo. Un ensayo en los fundamentos de la filosofía de la mística»: Juan Martín Velasco, La experiencia mística. Estudio interdisciplinar. Madrid: Trotta, 285-309.

—, (2018). «Notas sobre el centro del ser humano y su capacidad de Dios» en: M. I. Rodríguez Fernández (dir.), Consciencia e interioridad. Ávila: CITeS, 2018, 25-33.

—, (2017). "Sobre las inquietudes del corazón» en: Revista Corintios XIII 168 (2018), 102-117. 961978.

Martín Velasco, J. (1995). El encuentro con Dios. Madrid: Caparrós Editores.

—, (1999). El fenómeno místico. Estudio comparado. Madrid: Trotta.

-, (1996). Fenomenología de la soledad: Iglesia Viva 186.

—, (2006). Introducción a la fenomenología de la religión. Madrid: Trotta.

-, (2007). La experiencia cristiana de Dios. Madrid: Trotta.

-, (1978). La religión en el mundo. Madrid: Sígueme.

-, (2007). Mística y humanismo. Madrid: PPC.

-, (2005). Revelación y fe desde la perspectiva de las ciencias de las religiones, en: VV. AA., La fe. Madrid: PPC-Fundación Santa María.

\section{BiBLIOGRAFÍA COMPLEMENTARIA}

García Guerrero, B. 82016). La relación religiosa en la obra de Emmanuel Levinas, Universidad Pontificia de Salamanca.

Lacoste, J.-Y. (dir) (2007). Diccionario de Teología, (trad. Pérez de Tudela, Jorge). Madrid: Ed Akal.

Levinas, E. (2012). Totalidad e infinito: ensayo sobre la exterioridad. Trad. M. GarcíaBaró. Salamanca: Sígueme.

-, (2008). Dios, la muerte y el tiempo (trad. María Luisa Rodríguez Tapia). Madrid: Ediciones Cátedra.

—, (2013). Escritos inéditos 1 (trad. Miguel García-Baró, Mercedes Huarte y Javier Ramos). Madrid: Trotta.

Rosales Meana, D. (2018). «Hablar en silencio. Cuatro Navegaciones», en: VV. AA., La filosofía y el Bien. Madrid: Ápeiron Ediciones, 103-115. 
BIBLIOGRAFÍA Y SISTEMA DE REFERENCIAS DE LAS OBRAS DE LOS MÍSTICOS

Teresa de Jesús ( $\left.{ }^{5} 2000\right)$. Obras completas. Burgos: Editorial de Espiritualidad.

-, Libro de Moradas o Castillo Interior (1M, primera morada; 2M, segunda morada, etc.).

Juan de la Cruz ('2009). Obras completas. Madrid: Editorial de Espiritualidad.

-, Llama de amor viva $\mathrm{B}$

Universidad Pontificia Comillas

Angélica Morales Arizmendi

angelicamstj@gmail.com

[Artículo aprobado para publicación en enero de 2019] $]^{79}$

79 Revisado posteriormente para la publicación. 